Original Article

\title{
REVISION SURGERY IN LUMBAR DEGENERATIVE DISEASE
}

\author{
Hosni H. Salama, Tarek H. Abdelbary \\ Neurosurgery Departement, Faculty of Medicine, Zagazig University, Zagazig, Egypt
}

Corresponding Author:

Hosni Hassan Salama

Neurosurgery

Departement, Faculty of

Medicine, Zagazig

University, Zagazig, Egypt hosni10565@yahoo.com

Submit Date Revise Date Accept Date

2019-01-24 2019-02-20 2019-02-24

\section{ABSTRACT}

Introduction: Lumbar degenerative disease is a common health problem all over the world and the need for revision surgery is still high with variable results. The aim of the work: Is to evaluate the clinical and radiologic outcome in cases of redo surgery for lumbar degenerative pathology and to specify which pathology is responding well to revision surgery.

Patients and methods: Forty eight patients were operated upon for revision of previous failed back surgery in Zagazig University Hospitals from August 2014 to April 2017. Selection of patients for revision surgery depends on confirmed radiological and clinical compression or instability. All patients were operated and followed for at least 6 months after surgery. VAS score was used as a tool for evaluation of back and leg pain.

Results: There were 48 patients; with a mean age of 46.7 years (range 22-78).There were 29 males and 19 females. The dominant symptoms were unilateral sciatica in 30 , bilateral in 11 , low back pain in 23 patients .Neurogenic claudication was present in 4 cases. Type of surgery was redo discectomy in 31 cases, revision decompression for spinal canal stenosis in 4 cases, and posterior lumbar interbody fusion in 13 cases, with success rate of $96.8 \%, 75 \%$ and $84.6 \%$ respectively regarding improvement after surgery.

Conclusion: Revision surgery of lumbar degenerative diseases gives excellent results provided that the patients are properly selected.

Keywords: Lumbar degenerative disease. Revision surgery. Outcome. Abbreviations:VAS=Visual Analog scale, PLIF= Posterior lumbar interbody fusion, IVD= Intervertebral disc.

\section{INTRODUCTION}

Tis he definition of revision surgery in lumbar degenerative disorders, applies for patients presenting with non-relieved symptoms or recurrence of symptoms after a variable period of pain free interval [1].The reason for repeated surgery varies but it is generally undesired event [2].

Posterior lumbar decompression and fusion is a common procedure for treating lumbar degenerative disorders. Many of those patients had undergone the surgery at least one time before [3].

Careful patient selection and meticulous surgical techniques are essential requirements to avoid revision in lumbar spine surgery, however the need for surgery cannot be avoided in many cases [4].

The reported incidence for revision in lumbar disc surgery varies from 2 to $19 \%$ [5-8] depending greatly on patient selection and surgical technique used in the first surgery [1].

The morphology of the intervertebral disc (IVD) displacement was found to affect rate of recurrence being higher in protruded disc and lower in extruded and sequestrated ones [9].

Certain differences exists between primary and revision surgery including reduced tissue vascularity, epidural fibrosis with associated risk of incidental durotomy, adjacent segment 
disease after stabilization or instability after extensive laminectomy [4].

There was a wide range of success rates in the literature regarding revision lumbar surgery [10-13] and that may be explained by the difference in patient characteristics, technique, and even the definition of success [14].

Our aim is to evaluate the clinical and radiologic outcome in cases of revision surgery done for lumbar degenerative pathology and to specify which pathology is responding well to revision surgery.

\section{PATIENTS AND METHODS}

Forty eight patients were operated upon for revision of previous failed back surgery in Zagazig University Hospitals from August 2014 to April 2017. Written informed consent was obtained from all participants and the study was approved by the research ethical committee of Faculty of Medicine, Zagazig University. The work was carried out in accordance with The Code of Ethics of the World Medical Association (Declaration of Helsinki) for studies involving humans.

These patients were operated for lumbar degenerative disease before at different centers with no improvement or recurrence of symptoms. They were subjected to full history taking, clinical and radiologic evaluation. The decision of revision surgery was taken according to definite clinical and radiologic data with the inclusion criteria of :

- 1.Persistant severe low back pain and/or sciatica inspire of sufficient conservative measures including rest, drug therapy, and physiotherapy.

- 2.Radiologic evidence of neural compression and/or instability.

- 3.Fittness for surgery and patient consent to approve surgery.

- The exclusion criteria were:

- 1. No clinical or radiologic evidence of neural compression and/or instability

- 2. Patients unfit for or refusing surgery.

- 3. Hardware failure of previous lumbar fixation.

- 4. Previous postoperative complications (spondylodiscitis)

- All patients were prepared for surgery as a routine preoperative fitness and surgery was performed under general anesthesia in the prone position.

Clinical evaluation includes meticulous general and local examination for the previous wound, range of movement (ROM), straight leg raising (SLR) and examination of motor, sensory and reflex changes

Radiological studies included pain $x$-ray anteroposterior (to show the limits of previous bony decompression), lateral dynamic views (to confirm or exclude instability), CT lumbosacral spine was a complimentary tool in some cases but MRI lumbosacral spine with contrast was done for all cases and it was useful for good delineation of soft tissue pathology and neural element compression.

The types of surgery were microdiscectomy, laminectomy and posterior lumbar interbody fusion (PLIF) according to the recurrent pathology whether it was recurrent disc, recurrent stenosis or instability.

Follow up clinically was done immediate postoperatively, 2 weeks and 6 months later, and radiologically immediate postoperative and after 6 months in cases of fixation or in the presence of complications.

We used the questionnaire of Wong et al 2001 [11]. The questionnaire included pain assessment using a visual analog scale (VAS), frequency of medication, and the status of working and daily activity. The operative results were classified as "excellent" (if the patient felt no pain, required no medication, and returned to his or her previous work; "good" (if the patient felt pain was much improved, returned to work, and required little medication); "fair" (if patient's pain improved moderately, he or she took frequent medication, and changed to lighter work); "no improvement"; or "worse" being the poorest result. "Excellent" or "good" results were considered successful with the others being considered failures.

\section{RESULTS}

There were 48 patients; with a mean age of 46.7 years (range 22-78). There were 29 males and 19 females. The dominant symptoms were unilateral sciatica in 30 , bilateral in 11 , low back pain in 23 patients .Neurogenic claudication was present in 4 cases. Type of surgery was redo discectomy in 31 cases, revision decompression for spinal canal 
stenosis in 4 cases, and posterior lumbar interbody fusion in 13 cases, with success rate of $96.8 \%, 75 \%$ and $84.6 \%$ respectively regarding improvement after surgery.
Data were collected and presented in the following tables.

Table 1 Clinical presentation for all cases of revision lumbar surgery

\begin{tabular}{|l|l|l|}
\hline Symptom & Number & \% \\
\hline Low back pain & 23 & 47.9 \\
\hline Sciatica & 41 & 85.4 \\
\hline Motor deficit & 04 & 08.3 \\
\hline Sphincteric disturbance & 02 & 04.2 \\
\hline
\end{tabular}

Table 2 Surgical techniques.

\begin{tabular}{|l|l|l|}
\hline Surgical technique & Number & Percent \\
\hline Microdiscectomy & $31 / 48$ & 64.6 \\
\hline Laminectomy & $4 / 48$ & 8.3 \\
\hline $\begin{array}{l}\text { PLIF(includes discectomy and } \\
\text { interbody fusion) }\end{array}$ & $13 / 48$ & 27.1 \\
\hline
\end{tabular}

Table 3 Complications of different surgical techniques

\begin{tabular}{|l|l|l|}
\hline Complication & Number & Percent \\
\hline Dural tear & 4 & 8.3 \\
\hline Wound infection & 6 & 12.5 \\
\hline Neurologic deterioration & 2 & 4.1 \\
\hline
\end{tabular}

Table 4 Clinical outcome per pathology.

\begin{tabular}{|l|l|l|c|}
\hline outcome & pathology & Number & \% \\
\hline excellent & Disc & $27 / 31$ & 87.1 \\
& Stenosis & $2 / 4$ & 50.0 \\
& instability & $8 / 13$ & 61.5 \\
\hline good & Disc & $3 / 31$ & 9.7 \\
& Stenosis & $1 / 4$ & 25.0 \\
& instability & $3 / 13$ & 23.1 \\
\hline fair & Disc & $1 / 31$ & 3.2 \\
& Stenosis & $1 / 4$ & 25.0 \\
& instability & $1 / 13$ & 7.7 \\
\hline poor & Disc & $0 / 31$ & 0.0 \\
& Stenosis & $0 / 4$ & 0.0 \\
& instability & $1 / 13$ & 7.7 \\
\hline
\end{tabular}

\section{DISCUSSION}

Revision surgery may be indicated due to failure of prior surgery or new spine pathology. Many authors described potential causes of revision surgery, these include improper selection of patients, incorrect initial diagnosis, performance of the wrong type of procedure, use of poor technique, failure to achieve surgical goals of index procedure, iatrogenic complications, and new sources of pain such as that from progressive disease [15].Wrong level surgery may be a cause of revision surgery due to persistence of symptoms.

There are many factors involved in revision spinal surgery that the clinician must consider. As with any surgical procedure, proper patient selection is imperative in achieving a successful outcome. 
In addition, the preoperative workup in the potential candidate for revision spinal surgery should include evaluation for scar tissue, instability, and possible new lesions. Only candidates in whom adequate course of conservative therapy has failed should be considered for revision surgery [4].

Waddell et al, 1979. [16] verified that the success rate in revision spinal surgery decreased in relation to the number of re interventions.

Fritsch et al, 1996. [17] reported $47 \%$ poor results in patients with multiple revisions. Kim et al, 1992 [18].stated a 55\% success rate for re-revision surgery compared to a $66 \%$ success rate for revision surgery, but this difference in success rates was not significant [11].

Baba et al, 1995 [1] concluded also that first time revision had a favorable outcome

The most common complaint in our series was sciatic pain $(85.4 \%)$ of patients because this complaint correlated well with good prognosis as it means mostly radicular compression which could be relieved surgically.

Low back pain was more marked in cases of instability as the main complaint with or without sciatica. We did not reoperate because of LBP except if there is instability Sphincteric disturbance dating since previous surgery did not improve even after good decompression.

We did not included cases with hardware failure because it has different etiology and pathogenesis.

MRI with Gadolinium was the standard imaging technique in our study for detection of soft tissue pathology and neural compromise, while plain X-Ray lumbosacral spine anteroposterior, lateral with flexion, lateral with extension views were used as a radiologic method for confirmation or exclusion of instability.

Herniated disc should not enhance while epidural scar did after MRI with gadolinium, this is very important because the prognosis of surgery for epidural scarring is very bad [17].

Intraoperative difficulties were mainly epidural fibrosis and disturbance of normal anatomy and this was overcomed by meticulous and tedious dissection and a fluoroscopic guidance if needed.

We did not try to peel the epidural fibrosis from the dura completely because of its significant risk of dural injury. Many authors concluded the significant increase in the incidence of incidental durotomy after revision lumbar spine surgery [19-21].

The incidence of incidental durotomy in our study was $8.4 \%$ and this is similar to the incidence in the study of Cammisa et al, 2000[19], Morgan-Hough et al 2003[9] reported incidence of $14.3 \%$ in revision surgery and it was $17.4 \%$ in the study of Stalke et al 1989 [22] however there was no long term effects of this complication and all cases were dealt with intraoperatively by primary repair.

The most critical technical step in revision surgery is safely establishing a plane between the dura and the scar tissue present from the index procedure. Techniques for doing so include working from areas of normal (unscarred) anatomy to areas of abnormal (scarred) anatomy, reaching a plane between scar tissue and dura mater. A curette can be used to define the plane between epidural scar tissue and residual bone [14].

The rate of incidental durotomy is increased in revision surgery as compared with primary surgery due to the presence of scar tissue, greater difficulty in obtaining adequate visualization, and dural adhesions [19].

Our aim was to relieve neural compression, so if there is epidural fibrosis not compressing the thecal sac or roots, no need was present to attempt separation from the dura.

The incidence of superficial wound infection was $12.5 \%$ of cases and this was explained by many authors to be due to devasclarization of soft tissues in the index surgery [4].

Wrong level index procedure was technically less complicated because of preservation of the normal anatomy at that level.

Recent conclusions indicated favorable prognosis for relapsed disc herniation [23-25]. Earlier reports of inferior results may be caused by presence of other pathology like foraminal stenosis, herniation at other level, epidural fibrosis and segmental instability [26-30]. 
The result of revision surgery for lumbar canal stenosis was $75 \%$ success in our study and all cases did not undergo fixation in the index surgery,

Because of the small number of cases, this percentage $(75 \%)$ may not be representing the actual incidence

Many authors stated that the addition of fixation in the absence of spondylolisthesis did not give advantage regarding reducing revision rate in lumbar canal stenosis [31,32].

According to individual pathology, success rate was highest with revision discectomy $(96.8 \%)$, followed by fixation $(84.6 \%)$ ) and lastly revision decompression (75\%). The success rate in lumbar decompression in lumbar canal stenosis may be lower than usual due to the small number included in this study

Tafazal and Sell 2006, [33] concluded that the baseline scores in revision surgery were similar to those undergoing a primary procedure and the change in scores (magnitude of success) was less for revision decompressions and fusions, but not for revision discectomies. These results were similar to our results in that the rate of success was higher with those cases of recurrent lumbar disc than those with recurrent lumbar canal stenosis and cases of instability needing PLIF.

The failure rate after primary surgery for lumbar degenerative disease was $37 \%$ after spinal fusion and $30 \%$ after decompression without fusion [34]. The reported incidence for revision in lumbar disc surgery varies from 2 to $19 \%$ depending greatly on patient selection and surgical technique used in the first surgery $[5,7,35,36]$.

The failure rate in our study including fair and bad results was $15.4 \%$ after fusion and $3.2 \%$ after discectomy only.

Conclusion: Revision surgery of lumbar degenerative diseases gives excellent results provided that the patients are properly selected.Theoutcome for revision for recurrent disc was better than for that for recurrent stenosis or new instability.

\section{Declaration of interest}

The authors report no conflicts of interest. The authors alone are responsible for the content and writing of the paper.

\section{Funding information}

None declared

\section{REFERENCES}

1-Baba, H., Chen, Q., Kamitani, K., Imura, S. and Tomita, K.,.Revision surgery for lumbar disc herniation. International orthopaedics, 1995; 19(2), pp.98-102.

2-Deyo, R.A., Martin, B.I., Kreuter, W., Jarvik, J.G., Angier, H. and Mirza, S.K.,.Revision surgery following operations for lumbar stenosis. The Journal of bone and joint surgery.American volume, 2011; 93(21), p.1979.

3-Zheng, F., Cammisa Jr, F.P., Sandhu, H.S., Girardi, F.P. and Khan, S.N.,. Factors predicting hospital stay, operative time, blood loss, and transfusion in patients undergoing revision posterior lumbar spine decompression, fusion, and segmental instrumentation. Spine, 2002; 27(8), pp.818-824.

4-Eichholz K. M. and Ryken T. C.; Complications of revision spinal surgery. Neurosurg Focus 2003;15 (3):Article 1.pp 1-4.

5-Connolly, E.S.,.Surgery for recurrent lumbar disc herniation. ClinNeurosurg, 1992;39, pp.211-216.

6-Fandino, J., Botana, C., Viladrich, A. and GomezBueno, J.,. Reoperation after lumbar disc surgery: results in 130 cases. Actaneurochirurgica, 1993;122(1-2), pp.102-104.

7- Hanley, J.E. and Shapiro, D.E.,. The development of low-back pain after excision of a lumbar disc. The Journal of bone and joint surgery.American volume, 1989;71(5), pp.719721.

8- Hoffman, R.M., Wheeler, K.J. and Deyo, R.A.,. Surgery for herniated lumbar discs. Journal of general internal medicine, 1993;8(9), pp.487496.

9- Morgan-Hough, C.V.J., Jones, P.W. and Eisenstein, S.M.,. Primary and revision lumbar discectomy: a 16-year review from one centre. The Journal of bone and joint surgery.British volume, 2003; 85(6), pp.871-874.

10-Fritsch, E.W., Heisel, J. and Rupp, S.,. The failed back surgery syndrome: reasons, intraoperative findings, and long-term results: a report of 182 operative treatments. Spine, 1996; 21(5), pp.626633.

11- Wong, C.B., Chen, W.J., Chen, L.H., Niu, C.C. and Lai, P.L. Clinical outcomes of revision lumbar spinal surgery: 124 patients with a minimum of two years of follow-up. Chang Gung medical journal, 2002; 25(3), pp.175-182.

12- Biondi, J. and Greenberg, B.J.,. Redecompression and fusion in failed back syndrome patients. Journal of spinal disorders, 1990;3(4), pp.362-369.

13- Phillips, F.M., Carlson, G.D., Bohlman, H.H. and Hughes, S.S.,. Results of surgery for spinal 
stenosis adjacent to previous lumbar fusion. Clinical Spine Surgery, 2000;13(5), pp.432-437.

14-Hulen, C.A.,.A review of the significance, indications, techniques, and outcomes of revision lumbar laminectomy surgery.In Seminars in Spine Surgery ,2008, December (Vol. 20, No. 4, pp. 270-276). WB Saunders.

15-Guyer, R.D., Patterson, M. and Ohnmeiss, D.D.,. Failed back surgery syndrome: diagnostic evaluation. JAAOS-Journal of the American Academy of Orthopaedic Surgeons, 2006;14(9), pp.534-543.

16-Waddell, G., Kummel, E.G., Lotto, W.N., Graham, J.D., Hall, H. and McCulloch, J.A.,.Failed lumbar disc surgery and repeat surgery following industrial injuries. The Journal of bone and joint surgery.American volume, 1979;61(2), pp.201-207.

17-Fritsch, E.W., Heisel, J. and Rupp, S.,. The failed back surgery syndrome: reasons, intraoperative findings, and long-term results: a report of 182 operative treatments. Spine, 1996;21(5), pp.626633.

18-Kim, S.S. and Michelsen, C.B.,.Revision surgery for failed back surgery syndrome. Spine, 1992;17(8), pp.957-960.

19-Cammisa Jr, F.P., Girardi, F.P., Sangani, P.K., Parvataneni, H.K., Cadag, S. and Sandhu, H.S., 2000.Incidental durotomy in spine surgery. Spine, 25(20), pp.2663-2667.

20-Jones, A.A., Stambough, J.L., Balderston, R.A., Rothman, R.H. and Booth, J.R.,.Long-term results of lumbar spine surgery complicated by unintended incidental durotomy. Spine, 1989; 14(4), pp.443-446.

21-Wang, J.C., Bohlman, H.H. and Riew, K.D.,. Dural tears secondary to operations on the lumbar spine. Management and results after a two-year-minimum follow-up of eighty-eight patients. JBJS, 1998; 80(12), pp.1728-32.

22-Stolke, D., Sollmann, W.P. and Seifert, V.,.Intraand postoperative complications in lumbar disc surgery. Spine, 1989;14(1), pp.56-59.

23-Ebeling, U., Kalbarcyk, H. and Reulen, H.J.,. Microsurgical reoperation following lumbar disc surgery: timing, surgical findings, and outcome in 92 patients. Journal of neurosurgery, 1989; 70(3), pp.397-404.

24-Suk, K.S., Lee, H.M., Moon, S.H. and Kim, N.H.,. Recurrent lumbar disc herniation: results of operative management. Spine, 2001;26(6), pp.672-676.
25-Herron, L.,. Recurrent lumbar disc herniation: results of repeat laminectomy and discectomy. Journal of spinal disorders, 1994;7(2), pp.161-166.

26-Jackson, R.K.,. The long-term effects of wide laminectomy for lumbar disc excision: a review of 130 patients. The Journal of bone and joint surgery.British volume, 1971;53(4), pp.609-616.

27-Law, J.D., Lehman, R.A. and Kirsch, W.M.,.Reoperation after lumbar intervertebral disc surgery. Journal of neurosurgery, 1978; 48(2), pp.259-263.

28-Jonsson, B. and Stromqvist, B.,. Repeat decompression of lumbar nerve roots. A prospective two-year evaluation. The Journal of bone and joint surgery.British volume, 1993;75(6), pp.894-897.

29-Bernard, J.T.,. Repeat lumbar spine surgery. Factors influencing outcome. Spine, 1993;18(15), pp.2196-2200.

30-Epstein, J.A., Lavine, L.S. and Epstein, B.S.,.Recurrent herniation of the lumbar intervertebral disk. Clinical Orthopaedics and Related Research ${ }^{\circledR}, 1967 ; 52$, pp.169-178.

31-Martin, B.I., Mirza, S.K., Comstock, B.A., Gray, D.T., Kreuter, W. and Deyo, R.A.,. Reoperation rates following lumbar spine surgery and the influence of spinal fusion procedures. Spine, 2007;32(3), pp.382-387.

32-Hu, R.W., Jaglal, S., Axcell, T. and Anderson, G.,.A population-based study of reoperations after back surgery. Spine, 1997;22(19), pp.22652270.

33-Tafazal, S.I. and Sell, P.J.,. Outcome scores in spinal surgery quantified: excellent, good, fair and poor in terms of patient-completed tools. European Spine Journal, 2006;15(11), pp.1653-1660.

34-Frymoyer, J.W., Matteri, R.E., Hanley, E.N., Kuhlmann, D. and Howe, J.,.Failed lumbar disc surgery requiring second operation.A long-term follow-up study. Spine, 1978; 3(1), pp.7-11.

35-Fandino, J., Botana, C., Viladrich, A. and Gomez-Bueno, J.,. Reoperation after lumbar disc surgery: results in 130 cases. Actaneurochirurgica, 1993;122(1-2), pp.102-104.

36- Hoffman, R.M., Wheeler, K.J. and Deyo, R.A.,.Surgery for herniated lumbar discs. Journal of general internal medicine, 1993; 8(9), pp.487496. 